\title{
REM Sleep Behavior Disorder in Children With Type 1 Narcolepsy Treated With Sodium Oxybate
}

Elena Antelmi, MD, PhD, Marco Filardi, PsyD, PhD, Fabio Pizza, MD, PhD, Stefano Vandi, RPSGT, Monica Moresco, MSc, PhD, Christian Franceschini, PsyD, PhD, Michele Tinazzi, MD, PhD, Raffaele Ferri, MD, PhD, and Giuseppe Plazzi, MD, PhD

Neurology ${ }^{\circledR}$ 2021;96:e250-e254. doi:10.1212/WNL.0000000000011157

\section{Abstract}

\section{Objective}

To study the effect of stable treatment with sodium oxybate (SO) on nocturnal REM sleep behavior disorder (RBD) and REM sleep without atonia (RSWA) that severely affected children with type 1 narcolepsy (NT1).

\section{Methods}

Nineteen children and adolescents with NT1 (9 female, mean age $12.5 \pm 2.7$ years, mean disease duration $3.4 \pm 1.6$ years) underwent neurologic investigations and videopolysomnography (v-PSG) at baseline and after 3 months of stable treatment with SO. v-PSG was independently analyzed by 2 sleep experts to rate RBD episodes. RSWA was automatically computed by means of the validated REM sleep atonia index (RAI).

\section{Results}

Compared to baseline, RAI significantly improved $(p<0.05)$ and complex movements during REM sleep were remarkably reduced after stable treatment with SO. Compared to baseline, children also reported improvement in clinical complaints and showed a different nighttime sleep-stage architecture.

\section{Conclusions}

RBD and RSWA improved after treatment with SO, pointing to a direct role of the drug in modulating motor control during REM sleep.

\section{Classification of Evidence}

This study offers Class IV evidence of the positive effect of SO on modulation of muscle atonia during REM sleep in children with NT1 because of the absence of a control group.

\author{
Correspondence \\ Dr. Plazzi \\ giuseppe.plazzi@unibo.it
}

$\rightarrow$ Class of Evidence

Criteria for rating

therapeutic and diagnostic studies

NPub.org/coe

\section{- Videos}




\section{Glossary}

iRBD = idiopathic RBD; NREM = non-REM; NT1 = type 1 narcolepsy; RAI = REM atonia index; RBD = REM sleep behavior disorder; RSWA = REM sleep without atonia; $\mathbf{S O}=$ sodium oxybate; $\mathbf{v - P S G}=$ video-polysomnography.

Type 1 narcolepsy (NT1) is a central disorder of hypersomnolence that is characterized by sleep attacks, cataplexy, hypnagogic/hypnopompic hallucinations, sleep paralysis, and disrupted nocturnal sleep and linked to hypocretin-1 deficiency. ${ }^{1}$

REM sleep behavior disorder (RBD) has specific features in children with NT1, and video-polysomnography (v-PSG) disclosed almost repetitive gesturing/behaviors emerging during dissociated REM sleep in almost $30 \%$ of a cohort of 40 children. ${ }^{2}$ In these children, RBD occurs in correlation with decreased muscle atonia during REM sleep ${ }^{2}$; indeed, REM sleep without atonia (RSWA) is a sensitive and specific biomarker for NT1 in children. ${ }^{3}$

Because sodium oxybate (SO), a first-line treatment of NT1, has recently been reported to be effective in idiopathic RBD $(\mathrm{iRBD})^{4,5}$ and in modulating muscle activity during REM sleep in narcolepsy, ${ }^{6,7}$ the aim of this study was to evaluate the effect of this drug on nocturnal motor activity/behavior during REM sleep in children with NT1.

\section{Methods}

Nineteen children with a final diagnosis of NT1 according to international diagnostic criteria ${ }^{1}$ ( 9 female, mean age $12.5 \pm$ 2.7 years, mean disease duration $3.4 \pm 1.6$ years) were analyzed at baseline (drug free) and after at least 3 months of stable treatment with 6 to $8 \mathrm{~g} \mathrm{SO}$ ( $\mathrm{SO}$ was titrated on the basis of the patient's improvement, mean dose $6.4 \pm 1.2 \mathrm{~g}$ ). Extensive neurologic investigations and v-PSG were performed both at baseline and after treatment.

The v-PSG included at least 3 EEG channels (frontal, central, and occipital leads, referred to the contralateral mastoid), bilateral electro-oculogram, submentalis and anterior tibialis EMG, respiratory parameters, and ECG. PSG signals were sampled at $256 \mathrm{~Hz}$ and stored on hard disk in European data format for further analysis. Sleep stages were scored according to standard criteria. ${ }^{8}$ RSWA was evaluated by means of the REM atonia index (RAI) using the validated automatic analysis implemented in Hypnolab version 1.2. RAI can vary from 0 , which means complete absence of EMG atonia, to 1, which means stable EMG atonia.

The second-night v-PSGs were reviewed at baseline and after treatment for the classification of motor episodes by 2 sleep experts, who reached a mean interscorer agreement of 0.91 ( $p$ $=0.001)$. Briefly, as better detailed previously, ${ }^{2}$ we identified elementary movements as (1) small, brief ( $<5$ seconds), and apparently nonpurposeful movements and (2) stereotypies, automatism-like events. Complex behaviors instead identified purposeful behavior that seem to express a participant's mentation.

\section{Statistical Analysis}

Data were explored with descriptive statistics (mean \pm SD and frequency). Differences from baseline to follow-up evaluation in clinical and neurophysiologic data were assessed by means of the Student $t$ test for paired samples and the McNemar test. Values of $p<0.05$ were considered statistically significant; due to the exploratory nature of the study, $\alpha$ adjustments were not performed. Statistical analyses were conducted with IBM SPSS Statistics 19 software (SPSS, Inc, Chicago, IL).

\section{Standard Protocol Approvals, Registrations, and Patient Consents}

We received approval from the local ethical standards committee on human studies (No. 17009), and written informed consent was obtained from all patients (or guardians of patients) participating in the study (consent for research).

We obtained authorization for disclosure (consent to disclose) of any recognizable persons in photographs or videos or other information that may be published.

\section{Data Availability}

Anonymized data will be shared by request from any qualified investigator.

\section{Results}

Compared to baseline, after stable treatment with SO, children improved in clinical complaints, showing a decrease in the Epworth Sleepiness Scale score (14.4 \pm 4.25 vs $7.8 \pm 2.59$; $\mathrm{T}$ $[18]=5.05, p<0.0001)$ and a different distribution of sleep stages, with a decrease in the percentage of non-REM (NREM) sleep stage $1(14.2 \pm 9.01$ vs $3.25 \pm 4.87$; $\mathrm{T}[18]=4.04, p<$ $0.0005)$ and in REM sleep (23.1 \pm 7 vs $13.1 \pm 6.45$; $\mathrm{T}$ [18] = $6.50, p<0.0001)$ and an increase in NREM sleep stage 3 (11.1 \pm 10.13 vs $53.9 \pm 17.96$; $\mathrm{T}[18]=-5.34, p<0.0001)$. RAI significantly increased from 0.68 to 0.81 ( $\mathrm{T}[18]=-3.27, p<$ $0.005)$. In analyses of motor events/behaviors during nighttime, it emerged that while simple motor episodes during NREM sleep tended to increase, complex movements during REM sleep decreased, although these observations did not reach statistical significance. Data are reported in the table.

Figures 1 and 2 show an example of v-PSG of a child with NT1 at baseline and after $\mathrm{SO}$, respectively. 
Table Neurophysiologic Findings

\begin{tabular}{|c|c|c|c|}
\hline & Baseline, Mean \pm SD $(n=19)$ & After SO $(6.4 \pm 1.2 \mathrm{~g}),{ }^{a}$ Mean \pm SD $(n=19)$ & $p$ Value \\
\hline Sleep latency, $\min$ & $3.7 \pm 5$ & $12.1 \pm 7$ & $<0.005$ \\
\hline REM latency, min & $41.2 \pm 59.79$ & $22.0 \pm 44.08$ & NS \\
\hline Total sleep time, min & $443.8 \pm 59.65$ & $447.7 \pm 29.02$ & NS \\
\hline Sleep period, $\min$ & $495.9 \pm 40.85$ & $485.7 \pm 24.72$ & NS \\
\hline Sleep efficiency, \% & $89.6 \pm 9.82$ & $93.5 \pm 4.73$ & NS \\
\hline WASO, min & $52.1 \pm 51.60$ & $31.2 \pm 22.15$ & NS \\
\hline Stage N1, \% & $14.2 \pm 9.01$ & $3.2 \pm 4.87$ & $<0.0001$ \\
\hline Stage N2, \% & $35.6 \pm 9.14$ & $29.8 \pm 13.39$ & NS \\
\hline Stage N3, \% & $27.1 \pm 10.05$ & $53.9 \pm 17.96$ & $<0.0001$ \\
\hline Stage R, \% & $23.1 \pm 7$ & $13.1 \pm 6.45$ & $<0.0001$ \\
\hline PLMS index, $\mathrm{n} / \mathrm{h}$ & $11.1 \pm 10.13$ & $8.2 \pm 9.19$ & NS \\
\hline RAI & $0.68 \pm 0.16$ & $0.81 \pm 0.011$ & $<0.005$ \\
\hline
\end{tabular}

Symptoms and nocturnal episodes

\begin{tabular}{llllll}
\hline & \multicolumn{2}{c}{ ESS score $14.37 \pm 4.25, \%$} & ESS score $7.84 \pm 2.59, \%$ & Yes \\
\cline { 2 - 6 } & No & Yes & No & 26.0001 \\
\hline Hypnagogic hallucinations & 57.9 & 42.1 & 73.7 & 21.1 & NS \\
\hline Sleep paralysis & 89.5 & 10.5 & 78.9 & 0 & NS \\
\hline Simple motor episodes in NREM & 36.8 & 63.1 & 5.3 & 94.7 & NS \\
\hline Simple motor episodes in REM & 5.3 & 94.7 & 78.9 & 21.1 & NS \\
\hline Complex motor episodes in REM & 36.8 & 63.2 & NS \\
\hline
\end{tabular}

Abbreviations: ESS = Epworth Sleepiness Scale; NREM = non-REM; NS = nonsignificant; N1, N2, N3 = stage 1, 2, and 3 of NREM sleep; PLMS = periodic limb movements during sleep; RAI = REM atonia index; $\mathrm{SO}=$ sodium oxybate; $\mathrm{WASO}=$ wakefulness after sleep onset.

${ }^{a}$ Mean dosage of SO \pm SD.

\section{Discussion}

Our findings indicate that RAI significantly increased after stable treatment with SO in children with NT1, indicating an improvement in muscle atonia control during REM sleep. The parallel tendency for a decrease in motor events/ behaviors during REM sleep leads us to infer a direct role of $\mathrm{SO}$ in modulating motor control during REM sleep.

On the contrary, simple motor events showed a tendency to increase during NREM, in line with a large cohort study of 116 adults with NT1 evaluated after 2 months of SO treatment in whom an increase in brief $(<0.5$ seconds) motor chin EMG activation was seen during NREM sleep at lower doses (up to $4.5 \mathrm{~g}$ ) of $\mathrm{SO}{ }^{7}$

In our cohort, the significant increase in RAI implies that the decrease in motor episodes during REM sleep cannot be ascribed only to the reduction in the amount of REM sleep and the increase in deep sleep but reflects a direct effect of $S O$ in improving and stabilizing muscle atonia during REM sleep.
Previous studies showed a different effect on muscle tone modulation if $\mathrm{SO}$ was administered short term or long term in NT1. Short-term administration of SO did not show an immediate effect on chin muscle tone compared to baseline. ${ }^{9}$ Contrary to this, a single case report ${ }^{6}$ and a cohort study of 116 patients with narcolepsy-cataplexy ${ }^{7}$ showed a direct effect on muscle tone. ${ }^{7}$ In the cohort study, the effect seemed to be dose and sleep stage dependent, with low doses increasing short muscle activity in both NREM and REM sleep, while high doses decreased longer muscle activations $(>0.5 \mathrm{sec}-$ onds) during REM sleep.

This is quite compelling because it seems not to be the case in iRBD, for which systematic studies are lacking. However, a report of 2 adult male patients with violent iRBD showed the persistence of RSWA and RBD episodes at v-PSG, even if patients subjectively reported an improvement in symptoms. ${ }^{5}$ In particular, 1 patient reported that he could not recall dreams anymore. This allows us to suppose that the beneficial effect of SO in iRBD is likely related to the modification of dream mentation ${ }^{5}$ rather than to a direct action on muscle 
Figure 1 Video-Polysomnography of a Child With Type 1 Narcolepsy at Baseline (Drug Free)
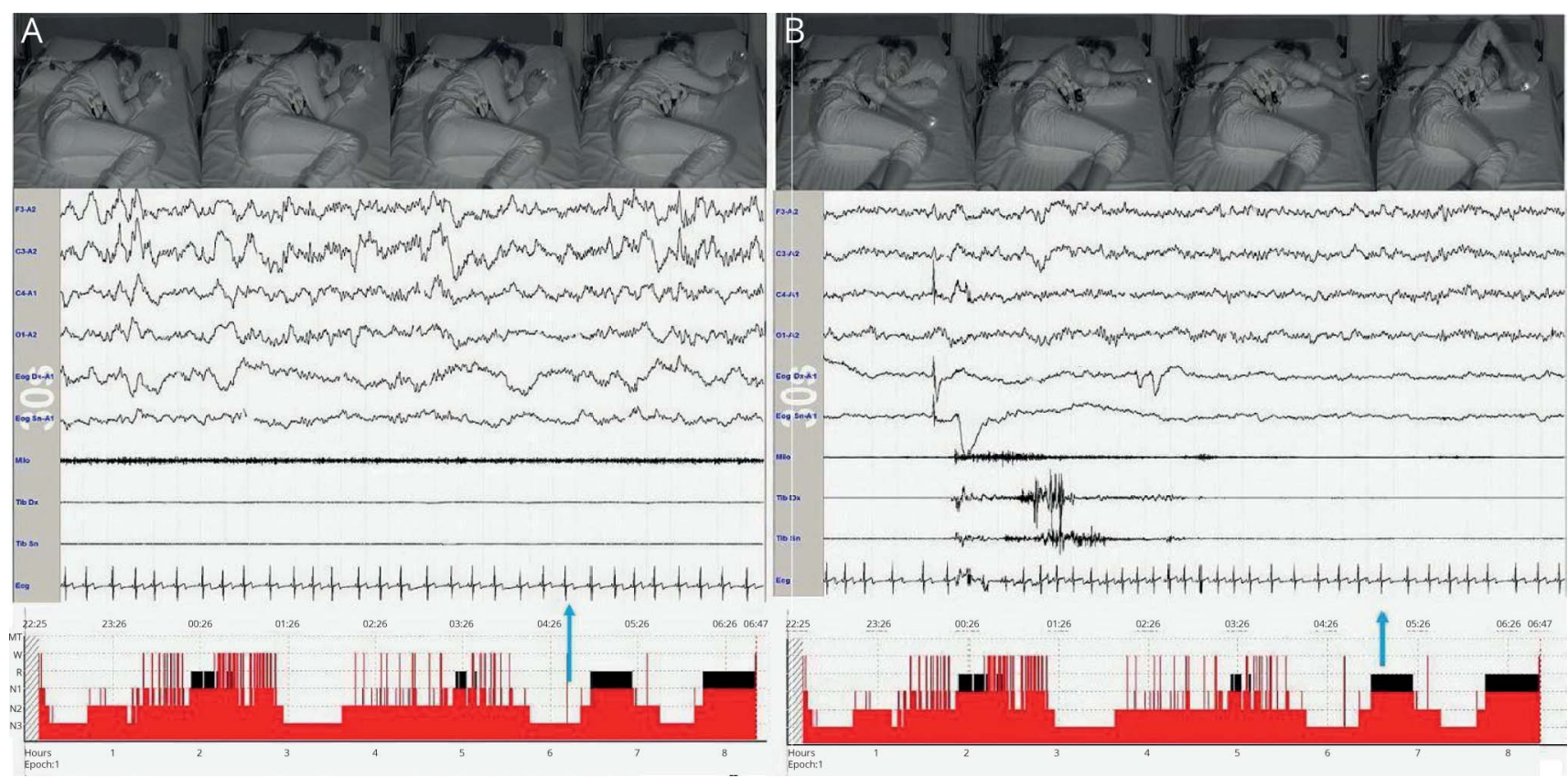

(A) Simple gesturing during non-REM sleep. (B) Complex gesturing during REM sleep (video segments and chin EMG channels).

activity. Two additional case reports in the literature show improvement of RBD episodes in iRBD with SO, but neurophysiologic parameters were not collected. ${ }^{4,10}$
The different effect on tone modulation and the effect on motor episodes by SO in children with NT1 confirm that even if $\mathrm{iRBD}$ and RBD within narcolepsy share overlapping

Figure 2 Video-Polysomnography of a Child With Type 1 Narcolepsy After 3 Months of Stable Treatment With Sodium Oxybate
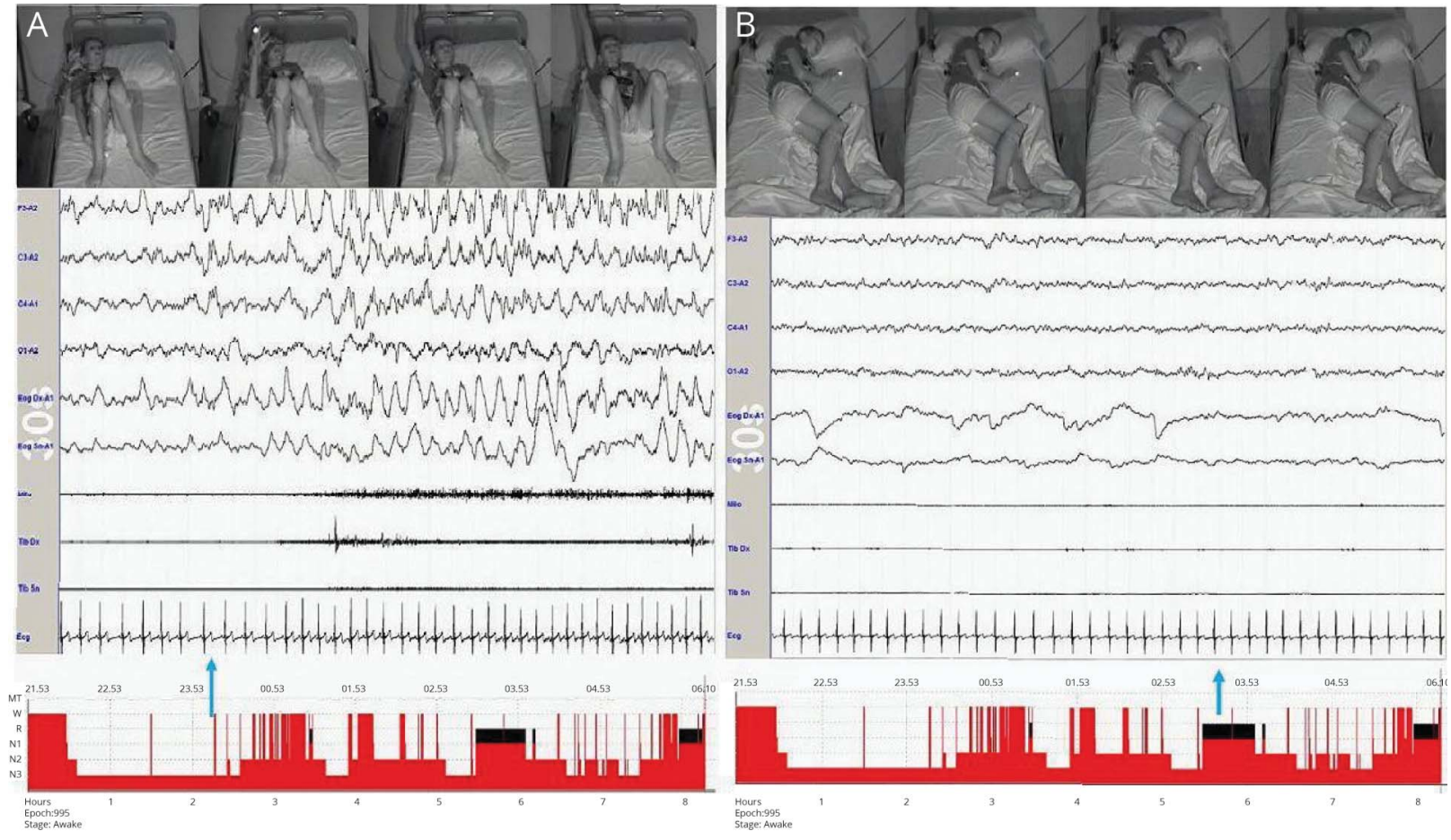

(A) Complex motor episodes, i.e., non-REM parasomnia (video segments and chin EMG channels). (B) Simple gesturing during REM sleep. 
features, they have different mechanisms. ${ }^{11}$ Indeed, motor behaviors during REM sleep in patients with NT1 are simpler and calmer and occur throughout the whole night, contrary to patients with iRBD in whom more vivid and energetic episodes are observed, mainly in the second half of the night. ${ }^{10}$ Episodes are also different from a neurophysiologic standpoint, with patients with narcolepsy presenting increased chin EMG tone and phasic activations in all sleep stages and dissociated EEG features and patients with iRBD having only RSWA. ${ }^{11}$

This study shows SO to be efficacious not only in treating clinical symptoms of narcolepsy but also in positively modulating motor activity during REM sleep, with the potential to reduce RBD episodes. The effect on muscle tone and on episodes during NREM is, however, still controversial; indeed, SO has been reported to trigger NREM parasomnia and to increase short muscle activations during NREM sleep at a lower dose. ${ }^{7}$ Similarly, in our cohort, we observed the tendency to increase simple movements in NREM sleep, putatively because of its GABAergic mechanism (videos 1 and 2 ).

SO promises to be useful in reducing RBD in children with NT1 by directly modulating muscle tone during REM sleep. Further studies are needed to confirm our findings in adults with NT1 and in those with iRBD.

\section{Study Funding}

No targeted funding reported.

\section{Disclosure}

The authors report no disclosures relevant to the manuscript. Go to Neurology.org/N for full disclosures.

\section{Publication History}

Received by Neurology February 12, 2020. Accepted in final form August 25, 2020.

\section{Appendix Authors}

\begin{tabular}{lll}
\hline Name & Location & Contribution \\
\hline $\begin{array}{ll}\text { Elena Antelmi, } \\
\text { MD, PhD }\end{array}$ & $\begin{array}{l}\text { University of Bologna } \\
\text { and University of } \\
\text { Verona, Italy }\end{array}$ & $\begin{array}{l}\text { Conception of the study, } \\
\text { acquisition and } \\
\text { interpretation of data, } \\
\text { drafting of the manuscript, } \\
\text { revision of the manuscript, } \\
\text { final approval of the } \\
\text { manuscript }\end{array}$ \\
& & \\
\end{tabular}

Appendix (continued)

\begin{tabular}{|c|c|c|}
\hline Name & Location & Contribution \\
\hline $\begin{array}{l}\text { Marco Filardi, } \\
\text { PsyD, PhD }\end{array}$ & $\begin{array}{l}\text { University of Bologna, } \\
\text { Italy }\end{array}$ & $\begin{array}{l}\text { Statistical analysis, } \\
\text { acquisition and } \\
\text { interpretation of data, } \\
\text { revision of the manuscript, } \\
\text { final approval of the } \\
\text { manuscript }\end{array}$ \\
\hline $\begin{array}{l}\text { Fabio Pizza, } \\
\text { MD, PhD }\end{array}$ & $\begin{array}{l}\text { University of Bologna, } \\
\text { Italy }\end{array}$ & $\begin{array}{l}\text { Acquisition and } \\
\text { interpretation of data, } \\
\text { revision of the manuscript, } \\
\text { final approval of the } \\
\text { manuscript }\end{array}$ \\
\hline $\begin{array}{l}\text { Stefano Vandi, } \\
\text { RPSGT }\end{array}$ & $\begin{array}{l}\text { Bellaria Hospital, } \\
\text { Bologna, Italy }\end{array}$ & $\begin{array}{l}\text { Acquisition and } \\
\text { interpretation of data, final } \\
\text { approval of the manuscript }\end{array}$ \\
\hline $\begin{array}{l}\text { Monica } \\
\text { Moresco, MSC, } \\
\text { PhD }\end{array}$ & $\begin{array}{l}\text { University of Bologna, } \\
\text { Italy }\end{array}$ & $\begin{array}{l}\text { Acquisition of data, Final } \\
\text { approval of the manuscript }\end{array}$ \\
\hline $\begin{array}{l}\text { Christian } \\
\text { Franceschini, } \\
\text { PsyD, PhD }\end{array}$ & $\begin{array}{l}\text { University of Parma, } \\
\text { Italy }\end{array}$ & $\begin{array}{l}\text { Acquisition of data, revision } \\
\text { of the manuscript, final } \\
\text { approval of the manuscript }\end{array}$ \\
\hline $\begin{array}{l}\text { Michele } \\
\text { Tinazzi, MD, } \\
\text { PhD; }\end{array}$ & $\begin{array}{l}\text { University of Verona, } \\
\text { Italy }\end{array}$ & $\begin{array}{l}\text { Revision of the manuscript, } \\
\text { final approval of the } \\
\text { manuscript }\end{array}$ \\
\hline $\begin{array}{l}\text { Raffaele Ferri, } \\
\text { MD, PhD }\end{array}$ & IRCSS Oasi, Troina, Italy & $\begin{array}{l}\text { Interpretation of data, } \\
\text { revision of the manuscript }\end{array}$ \\
\hline $\begin{array}{l}\text { Giuseppe } \\
\text { Plazzi, MD, PhD }\end{array}$ & $\begin{array}{l}\text { University of Bologna, } \\
\text { Italy }\end{array}$ & $\begin{array}{l}\text { Conception of the study, } \\
\text { interpretation of data, } \\
\text { revision of the manuscript, } \\
\text { final approval of the } \\
\text { manuscript }\end{array}$ \\
\hline
\end{tabular}

\section{References}

1. American Academy of Sleep Medicine. The International Classification of Sleep Disorders: Diagnostic \& Coding Manual. 3rd ed. Rochester, MN: American Academy of Sleep Medicine; 2014.

2. Antelmi E, Pizza F, Vandi S, et al. The spectrum of REM sleep-related episodes in children with type 1 narcolepsy. Brain 2017;140:1669-1679.3.

3. Bin-Hasan S, Videnovic A, Maski K. Nocturnal REM sleep without atonia is a diagnostic biomarker of pediatric narcolepsy. J Clin Sleep Med 2018;14:245-252.

4. Shneerson JM. Successful treatment of REM sleep behavior disorder with sodium oxybate. Clin Neuropharmacol 2009;32:158-159.

5. Moghadam KK, Pizza F, Primavera A, et al. Sodium oxybate for idiopathic REM sleep behavior disorder: a report on two patients. Sleep Med 2017;32:16-21.

6. Mayer G. Efficacy of sodium oxybate on REM sleep behavior disorder in a patient with narcolepsy type 1 . Neurology 2016;8724:2594-2595.

7. Mayer G, Rodenbeck A, Kesper K; International Xyrem Study Group. Sodium oxybate treatment in narcolepsy and its effect on muscle tone. Sleep Med 2017;35:1-6.

8. Berry RB, Albertario CL, Harding SM, et al; American Academy of Sleep Medicine. The AASM Manual for the Scoring of Sleep and Associated Events: Rules; Terminology and Technical Specifications, Version 2.5. Darien, IL: American Academy of Sleep Medicine; 2018.

9. Plazzi G, Pizza F, Vandi S, et al. Impact of acute administration of sodium oxybate on nocturnal sleep polysomnography and on multiple sleep latency test in narcolepsy with cataplexy. Sleep Med 2014;15:1046-1054.

10. Liebenthal J, Valerio J, Ruoff C, Mahowald M. A case of rapid eye movement sleep behavior disorder in Parkinson disease treated with sodium oxybate. JAMA Neurol 2016;731:126-127.

11. Antelmi E, Pizza F, Franceschini C, Ferri R, Plazzi G. REM sleep behavior disorder in narcolepsy: a secondary form or an intrinsic feature? Sleep Med Rev 2019;50:101254. 


\section{Neurology}

\section{REM Sleep Behavior Disorder in Children With Type 1 Narcolepsy Treated With Sodium Oxybate \\ Elena Antelmi, Marco Filardi, Fabio Pizza, et al.}

Neurology 2021;96;e250-e254 Published Online before print November 11, 2020

DOI 10.1212/WNL.0000000000011157

\section{This information is current as of November 11, 2020}

\section{Updated Information \&} Services

References

Subspecialty Collections

Permissions \& Licensing

Reprints including high resolution figures, can be found at: http://n.neurology.org/content/96/2/e250.full

This article cites 9 articles, 0 of which you can access for free at: http://n.neurology.org/content/96/2/e250.full\#ref-list-1

This article, along with others on similar topics, appears in the following collection(s):

Narcolepsy

http://n.neurology.org/cgi/collection/narcolepsy

Parasomnias

http://n.neurology.org/cgi/collection/parasomnias

Information about reproducing this article in parts (figures,tables) or in its entirety can be found online at:

http://www.neurology.org/about/about_the_journal\#permissions

Information about ordering reprints can be found online:

http://n.neurology.org/subscribers/advertise

Neurology ${ }^{\circledR}$ is the official journal of the American Academy of Neurology. Published continuously since 1951, it is now a weekly with 48 issues per year. Copyright Copyright ( 2020 The Author(s). Published by Wolters Kluwer Health, Inc. on behalf of the American Academy of Neurology.. All rights reserved. Print ISSN: 0028-3878. Online ISSN: 1526-632X.

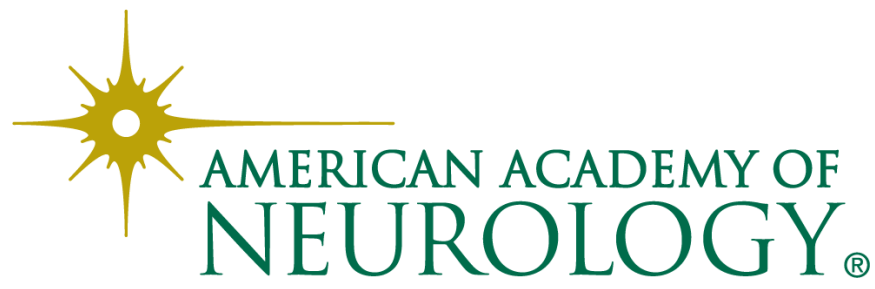

